\title{
Enhanced effect of gemcitabine by emodin against pancreatic cancer in vivo via cytochrome $\mathrm{C}$-regulated apoptosis
}

\author{
HUI CHEN*, WEITIAN WEI*, YAFEI GUO, AN LIU, HONGFEI TONG, \\ ZHAOHONG WANG, WEI TAN, JINXIANG LIU and SHENGZHANG LIN \\ Department of Surgery, The Second Affiliated Hospital of Wenzhou Medical College, \\ No. 109, West Xue-yuan Road, Wenzhou 325027, P.R. China
}

Received December 14, 2010; Accepted January 5, 2011

DOI: $10.3892 /$ or.2011.1174

\begin{abstract}
Gemcitabine is currently the best treatment available for pancreatic cancer, but causes high toxicity. Agents that can enhance the effects of gemcitabine with no or low toxicity are needed for the treatment of pancreatic cancer. Emodin, a natural anthraquinone derivative, is one such agent that has been shown to induce apoptosis in other tumor cells via down-regulation of $\mathrm{Bcl}-2 / \mathrm{Bax}$ and promoting the release of Cytochrome $\mathrm{C}(\mathrm{CytC})$, but with very low toxicity. The aim of this study was to evaluate whether emodin can enhance the effect of gemcitabine on pancreatic cancer in vitro and in vivo and to investigate the possible mechanisms of the enhancement. In vitro, emodin inhibited the proliferation of the SW1990 cell line and potentiated the apoptosis induced by gemcitabine, which was demonstrated by activation of caspase- 3 in the combination group. In vivo, tumors from nude mice subcutaneously injected with SW1990 cells and treated with a combination of emodin $(40 \mathrm{mg} / \mathrm{kg})$ and gemcitabine $(80 \mathrm{mg} /$ $\mathrm{kg}$ ) showed significant reductions in volume, Ki-67 proliferation index and expression of the Bcl-2/Bax ratio (compared with tumors from mice treated with sodium chloride, emodin alone $(40 \mathrm{mg} / \mathrm{kg})$ or gemcitabine alone $(125 \mathrm{mg} / \mathrm{kg})$, which induced increasing release of $\mathrm{CytC}$ from the mitochondria to the cytoplasm and triggered caspase- 3 activation leading to apoptosis. Taken together, our results suggest that emodin improved the anti-tumor effect of gemcitabine, even at a lower dose of gemcitabine which could decrease the toxicity of chemotherapy, on transplanted tumors of the SW1990 cell line through the enhancement of apoptosis induced by gemcitabine, the mechanism of which may be through down-regulation of
\end{abstract}

Correspondence to: Dr Shengzhang Lin, The Second Affiliated Hospital of Wenzhou Medical College, No. 109, West Xue-yuan Road, Wenzhou 325027, P.R. China

E-mail: wzf21sz@163.com

*Contributed equally

Key words: emodin, gemcitabine, apoptosis, Bcl-2, Bax, cytochrome $\mathrm{C}$ the $\mathrm{Bcl}-2 / \mathrm{Bax}$ ratio and promoting release of $\mathrm{CytC}$ from the mitochondria into the cytoplasm.

\section{Introduction}

Pancreatic cancer is a highly malignant tumor in alimentary system with very poor prognosis. One-year survival rate of patients with advanced pancreatic cancer was $8 \%$, and 5-year survival rate was $3 \%$ (1), with the median overall survival of only 6 months (2). Complete resection of the tumor is currently the only curative option but only $10-15 \%$ of patients present with localized, potentially resectable disease at the time of diagnosis (3). Previous research shows that gemcitabine, as a DNA nucleotide analogue, has a good effect on many solid tumors including pancreatic cancer, and as an adjuvant drug after curative-intent resection, can prolong disease-free survival to at least 6 months (4). Therefore, gemcitabine was used to treat advanced pancreatic cancer as a standard drug $(5,6)$. However, the effect of gemcitabine was limited with a low remission rate of about $10 \%(7,8)$, and median overall survival by adjuvant medication with gemcitabine after operation was only 22.1 months (4). Most patient would develop resistance to gemcitabine, which contains strong toxic side effect and is very expensive. Previous studies discovered many types of drugs that can strengthen the therapeutic effect of gemcitabine on pancreatic cancer (9-12). For the above reasons, it is valuable to find a drug which can potentiate the effect of gemcitabine but with low toxic effect and price.

Emodin (1,3,8-trihydroxy-6-methylanthraquinone) is a natural anthraquinone derivative isolated from Rheum palmatum L. Previous studies have demonstrated that emodin can inhibit cell growth and induce apoptosis in several types of tumor cells. Emodin, with low toxicity to normal cells, can induce tumor cells to produce reactive oxygen species (ROS), which results in down-regulation of Bcl-2 gene and up-regulation of Bax, leading to release of $\mathrm{CytC}$ from mitochondria, finally resulting in more tumor cell apoptosis $(13,14)$.

In this study, based on in vitro cell culture and transplanted tumor in athymic nu/nu mice, we investigated our hypothesis that emodin could significantly enhance the anti-tumor effect of gemcitabine on pancreatic cancer in vivo via CytCregulated apoptotic pathway. 


\section{Materials and methods}

Cell lines and animals. The human pancreatic cancer cell line SW1990 was purchased from American Type Culture Collection. Female athymic BALB/c nu/nu mice (4-6 weeks old) were purchased from Shang Hai Cancer Institute for tumor implantation. All animals were maintained in a sterile environment and cared for within animal experiment center of Wenzhou Medical College.

Drug and agents. Emodin was purchased from SigmaAldrich (St. Louis, MO, USA), dissolved in dimethylsulfoxide (DMSO). The final concentration of DMSO was $<0.1 \%$. Gemcitabine was purchased from Ely Lilly, dissolved in $0.9 \%$ sodium chloride. Rabbit anti-human anti-Bax, anti-Bcl-2 polyclonal antibodies, and anti-cytochrome $\mathrm{C}(\mathrm{CytC})$, anti-active caspase-3 monoclonal antibodies were bought from Abcam. In situ cell death detection kit was purchased from Roche, Germany.

Cell culture. The human pancreatic cancer cell lines SW1990 was maintained in RPMI-1640 supplemented with $10 \%$ fetal bovine serum, 100 units $/ \mathrm{ml}$ penicillin and $100 \mathrm{mg} / \mathrm{ml}$ streptomycin in a humidified incubator containing $5 \% \mathrm{CO}_{2}$ in air at $37^{\circ} \mathrm{C}$.

Cell growth assay. To assess the viability of cells, cell numbers were determined by the 3-(4,5-dimethylthiazol-2-yl)-2,5diphenyltetrazolium bromide assay (MTT) (Sigma, St. Louis, MO, USA), performed according to the method of Gerlier and Thomasset (15). Briefly, cells were plated at a density of $5 \times 10^{3}$ cells/well in 96-well microtiter plates. After treatment, $20 \mu 1$ of MTT solution [ $5 \mathrm{mg} / \mathrm{ml}$ in phosphate-buffered saline (PBS)] was added to each well and the plates were incubated. The supernatant was aspirated and the MTT formazan was dissolved in $150 \mu 1$ of DMSO. The plates were mixed for $10 \mathrm{~min}$ on a gyratory shaker, and absorbance was measured with an ELISA reader (BIO-Tek ELx800, Winooski, VT, USA) at a wavelength of $490 \mathrm{~nm}$. Experiment was repeated thrice.

Cell apoptosis assay. After cells had been exposed to gemcitabine $(20 \mu \mathrm{mol} / \mathrm{l})$ for $48 \mathrm{~h}$, emodin $(40 \mu \mathrm{mol} / \mathrm{l})$ for $48 \mathrm{~h}$ or their combinations ( $40 \mu \mathrm{mol} / 1$ emodin coincubated with $20 \mu \mathrm{mol} / 1$ gemcitabine) for $48 \mathrm{~h}$ at 6 -well plates, SW1990 cells were washed, harvested and counted. Cells $\left(1 \times 10^{5}\right)$ were re-suspended in $100 \mu \mathrm{l}$ binding buffer, before $10 \mu \mathrm{l}$ of Annexin $\mathrm{V}$ and $5 \mu \mathrm{l}$ of PI were added, and incubated in the dark for $15 \mathrm{~min}$ at room temperature, according to the manufacturer's instruction (Biosea, China). The apoptosis rate (\%) was determined with a cytometer (Epics AltraII, Beckman Coulter, USA). Cells were also viewed under an inverse fluorescent microscopy. Experiment was repeated thrice.

Caspase-3 activity assay. Caspase-3 activities were assayed using a Colorimetric Protease Assay Kit according to the manufacturer's instructions (Keygen Biotech, Nanjing, China). Briefly, $1 \times 10^{6}$ cells were harvested after treatment, washed three times with PBS and re-suspended in $50 \mu 1$ of the lysis buffer, kept on ice for $60 \mathrm{~min}$, and then centrifuged $(10,000 \mathrm{x} \mathrm{g}$,
$1 \mathrm{~min}$ at $4^{\circ} \mathrm{C}$ ). Supernatants containing $100 \mu \mathrm{g}$ of protein were incubated with $5 \mu$ l of enzyme specific colorimetric substrates Ac-DEVD-pNA $(2 \mathrm{mM})$, at $37^{\circ} \mathrm{C}$ for $4 \mathrm{~h}$. The colorimetric release of p-nitroaniline from the Ac-DEVD-pNA substrate was measured using a lightwave of $405 \mathrm{~nm}$ with an ELISA reader (BIO-Tek ELx800).

Pancreatic cancer xenograft tumor model. SW1990 cells in log-phase were digested with trypsin, and were finally re-suspended with serum-free culture medium. Tumor xenografts were established by subcutaneous inoculation of $2 \times 10^{6}$ SW1990 pancreatic cancer cells into the right abdominal flanks of BALB/c female mice (4-6 weeks old, 18-20 g in weight, purchased from Shanghai Laboratory Animal Center, Chinese Academy of Sciences, Shanghai, China). A total of 48 animals were randomly divided into four groups, 12 mice for each group, and were housed in Specific Pathogen Free (SPF) level laboratory. Three weeks after inoculation, when tumor grew to the size of largest diameter $\geq 5 \mathrm{~mm}$, mice received different treatments every three days. Animals in the emodin, gemcitabine, combination treatment group or control received intraperitoneal injection of $40 \mathrm{mg} / \mathrm{kg}$ emodin, $125 \mathrm{mg} / \mathrm{kg}$ gemcitabine, $40 \mathrm{mg} / \mathrm{kg}$ emodin plus $80 \mathrm{mg} / \mathrm{kg}$ gemcitabine or $0.9 \%$ sodium chloride, respectively. The body weight and tumor size of mice were measured every six days after drug treatments. Tumor size was calculated using the following formula: Volume $=(4 / 3) \pi[(\text { length }+ \text { width }) / 4]^{3}$. The inhibition ratio was calculated by the following formula: Inhibition rate $(\%)=[1$-(mean tumor volume of drug - treated mice before experiment - mean tumor volume of drug - treated mice at the end of the experiment)/(mean tumor volume of control mice before experiment - mean tumor volume of control mice at the end of the experiment)] x $100 \%$. One week after the final injection (Day 37), the animals were weighed and sacrificed. The subcutaneous tumors were excised and the tumor volume and weight were recorded. A part of the tumor tissue was formalin-fixed and paraffin-embedded for immunohistochemistry. The rest was frozen in liquid nitrogen for Western blot analysis. Ethical approval for this study was given by Ethics Committee at Wenzhou Medical College.

Ki-67 immunohistochemistry. Formalin-fixed, paraffinembedded sections $(4 \mu \mathrm{m}$ ) were stained with anti-Ki-67 (rabbit monoclonal clone SP6; NeoMarkers, Fremont, CA) antibody as described by Guha et al (16). Results were expressed as percentage of Ki- $67^{+}$cells \pm SE per field ( $\mathrm{x} 400$ magnification). A total of 10 fields (x400) was examined and counted from three tumors of each of the treatment groups.

TUNEL assay detect tumor apoptosis. To assess the degree of tumor apoptosis, we used the terminal deoxynucleotidyl transferase-mediated deoxyuridine triphosphate nick-end labeling (TUNEL) method after two weeks of therapy. TUNEL staining was performed by stantard methods with $4-\mu \mathrm{m}$ tissue section. Operated as shown in TUNEL kit steps, tissue section was added to TUNEL reaction solution at $37^{\circ} \mathrm{C}$ for $1 \mathrm{~h}$. Laser scanning confocal microscope under 400 -fold observation camera was used, with excitation wavelength $488 \mathrm{~nm}$ and emission wavelength $568 \mathrm{~nm}$. We observed 10 field vision of strongest fluorescence on each slice. 
Immunohistochemistry detection of apoptosis-related proteins: Bax, Bcl-2, CytC, active caspase-3. Sections were cut from paraffin embedded pancreatic cancer tissues. Immunostaining was performed using primary antibodies specific for Bax, Bcl-2, CytC and active caspase-3 with appropriate dilutions, followed by staining with appropriate HRP-conjugated secondary antibodies. The slides were developed in diaminobenzidine and counterstained with a weak solution of haematoxylin solution stain. The stained slides were dehydrated and mounted in permount and visualized on a microscope. Images were captured with an attached camera linked to a computer.

Isolation of mitochondria and cytoplasm of tumor tissue. Fresh tumor tissue were homogenated and then transfered to centrifuge tube, $800 \mathrm{x}$ g centrifugation for $5 \mathrm{~min}$ at $4^{\circ} \mathrm{C}$. Supernatant were collected and transferred to a new centrifuge tube. After $800 \times \mathrm{g}$ centrifugation for $5 \mathrm{~min}$ at $4^{\circ} \mathrm{C}$, we discarded the precipitate. The supernatant was transferred to a new centrifuge tube. After $12,000 \times \mathrm{g}$ centrifugation for $10 \mathrm{~min}$ at $4^{\circ} \mathrm{C}$, the supernatant containing cytoplasmic components and the sediment containing mitochondrial were separated and stored in $-80^{\circ} \mathrm{C}$ until use for detecting CytC in them by Western blot analysis.

Western blot detection of apoptosis-related protein in tumor tissue: Bax, Bcl-2, CytC and active caspase-3. Proteins were routinely extracted from tumor tissues using radioimmunoprecipitation assay (RIPA) buffer. The protein concentration was detected by bicinchoninic acid (BCA) assay. The proteins were then fractionated by SDS-PAGE, electrotransferred to PVDF membranes, blocked with 5\% non-fat milk, and then probed with primary antibodies and HRP-conjugated antirabbit secondary antibody. After washing, the bound antibody complexes were detected using ECL chemiluminescence reagent (Amersham).

Statistical analysis. Data are expressed as the means \pm SD. Statistical analysis was performed using SPSS software. Differences in mean values between groups were determined by one-way analysis of variance followed by two-tailed Student's t-test for unpaired samples, assuming equal variances. $\mathrm{P}<0.05$ was considered statistically significant.

\section{Results}

Emodin potentiates growth inhibition induced by gemcitabine in pancreatic cancer cells. We investigated the effect of combination of emodin and gemcitabine on cell viability by MTT assay. For these studies, SW1990 cells were treated with gemcitabine $(20 \mu \mathrm{mol} / \mathrm{l})$ for $48 \mathrm{~h}$, emodin $(40 \mu \mathrm{mol} / \mathrm{l})$ for $48 \mathrm{~h}$ or their combination [emodin $(40 \mu \mathrm{mol} / \mathrm{l})$ combined with gemcitabine $(20 \mu \mathrm{mol} / \mathrm{l})$ for $48 \mathrm{~h}$ ]. Viable cells were evaluated by MTT assay. We found that combination treatment with emodin plus gemcitabine resulted in more loss of cell viability than either emodin or gemcitabine alone in pancreatic cancer cells (Fig. 1).

Emodin sensitizes pancreatic cancer cells to gemcitabineinduced apoptosis in vitro. SW1990 cells were treated with

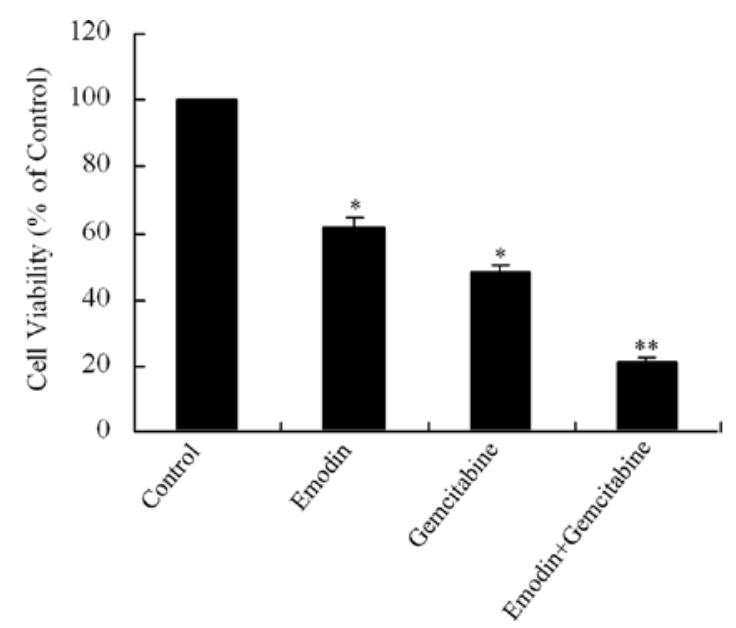

Figure 1. Cells were treated with gemcitabine $(20 \mu \mathrm{mol} / \mathrm{l})$ for $48 \mathrm{~h}$, emodin ( $40 \mu \mathrm{mol} / \mathrm{l})$ for $48 \mathrm{~h}$ or their combination [emodin $(40 \mu \mathrm{mol} / \mathrm{l})$ coincubated with gemcitabine $(20 \mu \mathrm{mol} / \mathrm{l})$ for $48 \mathrm{~h}$ ] and analyzed for viable cells by the MTT assay as described in Materials and methods. Data are presented as mean $\pm \mathrm{SE}$ of nine replicates from three independent experiments. ${ }^{*} \mathrm{P}<0.01$ compared with sodium chloride treatment; ${ }^{* *} \mathrm{P}<0.01$ compared with sodium chloride, emodin or gemcitabine treatment.

gemcitabine $(20 \mu \mathrm{mol} / \mathrm{l})$ for $48 \mathrm{~h}$, emodin $(40 \mu \mathrm{mol} / \mathrm{l})$ for $48 \mathrm{~h}$ or their combination [emodin $(40 \mu \mathrm{mol} / \mathrm{l})$ combined with gemcitabine $(20 \mu \mathrm{mol} / \mathrm{l})$ for $48 \mathrm{~h}$ ], before staining with Annexin V/PI for flow cytometry determination of the apoptotic rate and observation under fluorescent microscopy. We found that emodin increased the apoptotic rate from 4.6 to $21.6 \%$, while gemcitabine increased the apoptotic rate from 4.6 to $15.2 \%$, all with statistical significance $(\mathrm{P}<0.05)$. Combination of gemcitabine and emodin produced significantly more pronounced apoptosis compared with single-agent treatment $(29.6 \%, \mathrm{P}<0.05)$ (Fig. 2A and B). To further examine the ability of the combination therapy to induce apoptosis, caspase-3 activities in SW1990 cell line were evaluated. The combination of emodin and gemcitabine caused an additional increase in caspase-3 activity (Fig. 2C) by comparison with either agent alone. Next, we evaluated caspase-3 activation in both cell lines tested by Western blotting. The combined treatments also induced an additional activation of caspase-3 in SW1990 cells (Fig. 2D and E). These in vitro studies prompted us to conduct in vivo testing of our hypothesis.

Emodin augments the anti-tumor effect of gemcitabine in xenograft model of pancreatic cancer. The schematic overview of the study protocol is presented in Fig. 3A. SW1990 cell xenografts were established in athymic mice within 3 weeks and the nude mice were randomly divided into four experimental groups (12 mice in each group), which were respectively subjected to treatment with control $(0.9 \%$ sodium chloride), emodin (40 mg/kg), gemcitabine $(125 \mathrm{mg} / \mathrm{kg}$ ) or emodin $(40 \mathrm{mg} / \mathrm{kg})$ plus gemcitabine $(80 \mathrm{mg} / \mathrm{kg})$ every three days. At the beginning of the therapy, the tumor volume of all mice was $(0.38 \pm 0.05) \mathrm{cm}^{3}$, with no significant difference among groups $(\mathrm{P}>0.05)$. Emodin, gemcitabine or emodin plus gemcitabine treatments dramatically suppressed tumor growth and combination drug therapy was more effective in tumor 

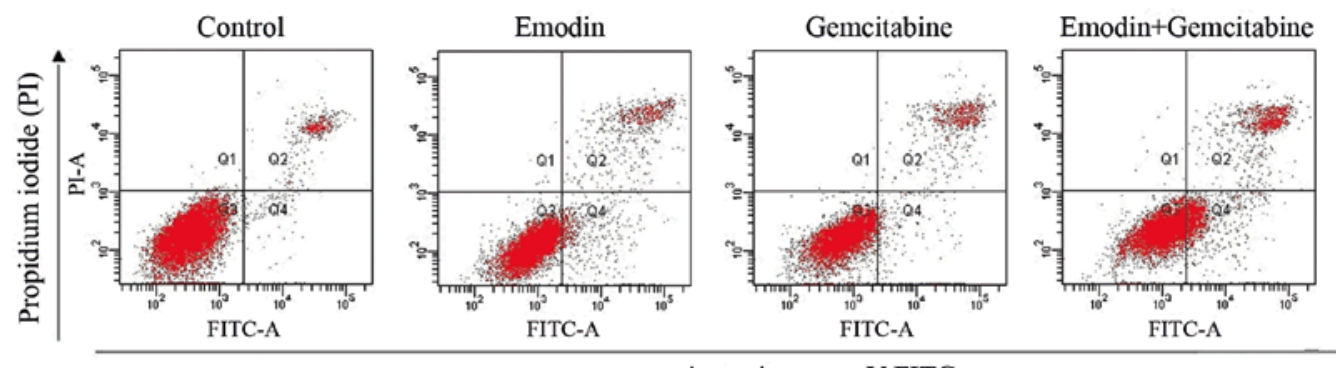

Annexin

V-FITC

(A)

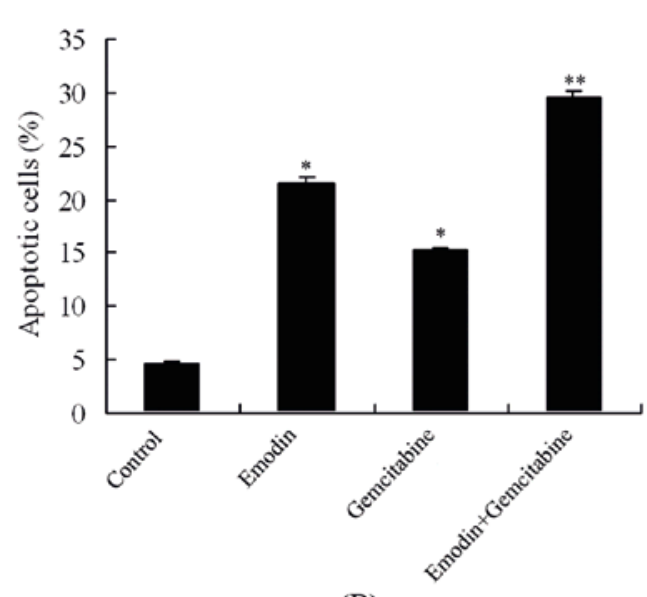

(B)

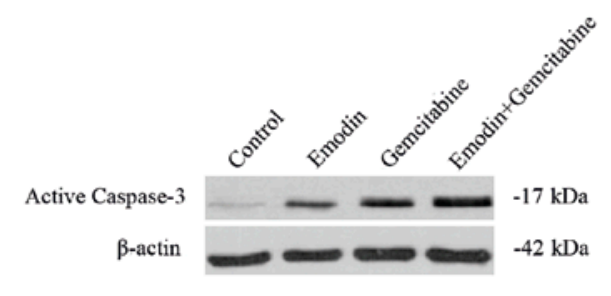

(D)

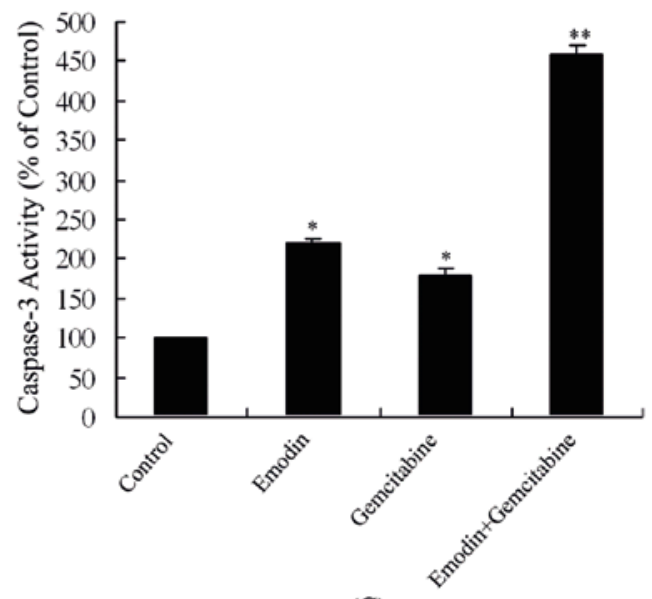

(C)

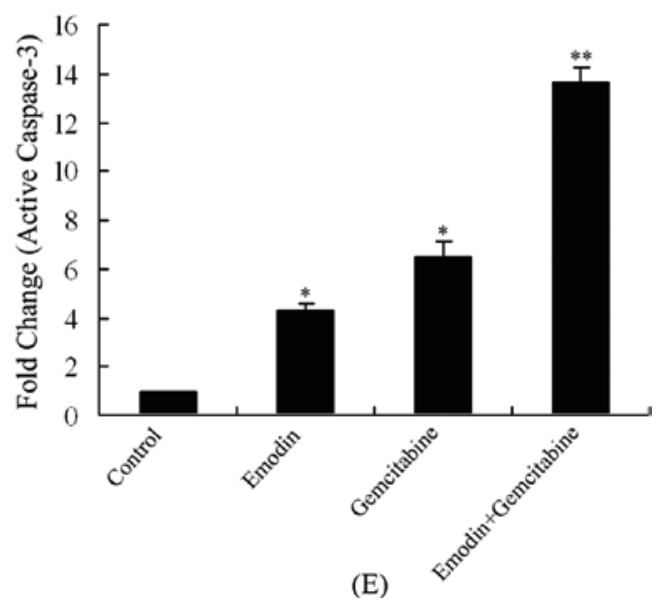

Figure 2. Induction of apoptosis in SW1990 cells treated with gemcitabine $(20 \mu \mathrm{mol} / \mathrm{l})$ for $48 \mathrm{~h}$, emodin $(40 \mu \mathrm{mol} / \mathrm{l})$ for $48 \mathrm{~h}$ or their combination [emodin ( $40 \mu \mathrm{mol} / \mathrm{l})$ coincubated with gemcitabine $(20 \mu \mathrm{mol} / \mathrm{l})$ for $48 \mathrm{~h}$ ] was determined by flow cytometry on Annexin V-FITC, and cells were also viewed under a fluorescent microscope. (A) Representative dot-plots illustrating apoptotic status in SW1990 cells. (B) The percentages of apoptotic cells. ${ }^{*} \mathrm{P}<0.05$, compared with control. ${ }^{* *} \mathrm{P}<0.05$, compared with single agent or control. (C) Cell lysates were assayed for caspase-3 activity as described in Materials and methods. Data are presented as the mean $\pm \mathrm{SE}$ of three independent experiments. ${ }^{*} \mathrm{P}<0.05$ compared with control; ${ }^{* *} \mathrm{P}<0.05$ compared with control, emodin or gemcitabine treatment. (D) Active caspase-3 protein levels were investigated. Western immunoblotting for $\beta$-actin protein was performed as loading control. (E) Quantified data of Western blot analysis are presented. ${ }^{*} \mathrm{P}<0.05$, compared with control. ${ }^{* *} \mathrm{P}<0.05$, compared with single agent or control.

inhibition than mono-therapy with either agent (Fig. 3B). One week after the final injection, mice were sacrificed and solid tumors were presented (Fig. 3C). Consistent with in vitro results, both tumor weight and volume were suppressed by mono-therapy with either agent or combination therapy with emodin plus gemcitabine compared with control, while combination treatment exhibited more efficient than single treatment $(\mathrm{P}<0.05)$ (Table I). These results demonstrated that emodin and gemcitabine combination treatment showed efficient tumor growth suppression in pancreatic tumor inoculated mice.

TUNEL staining shows emodin potentiates tumor cell apoptosis by gemcitabine. We next examined the expression of the cell proliferation marker Ki-67. The results in Fig. 4A and $\mathrm{B}$ show that emodin in combination with gemcitabine 


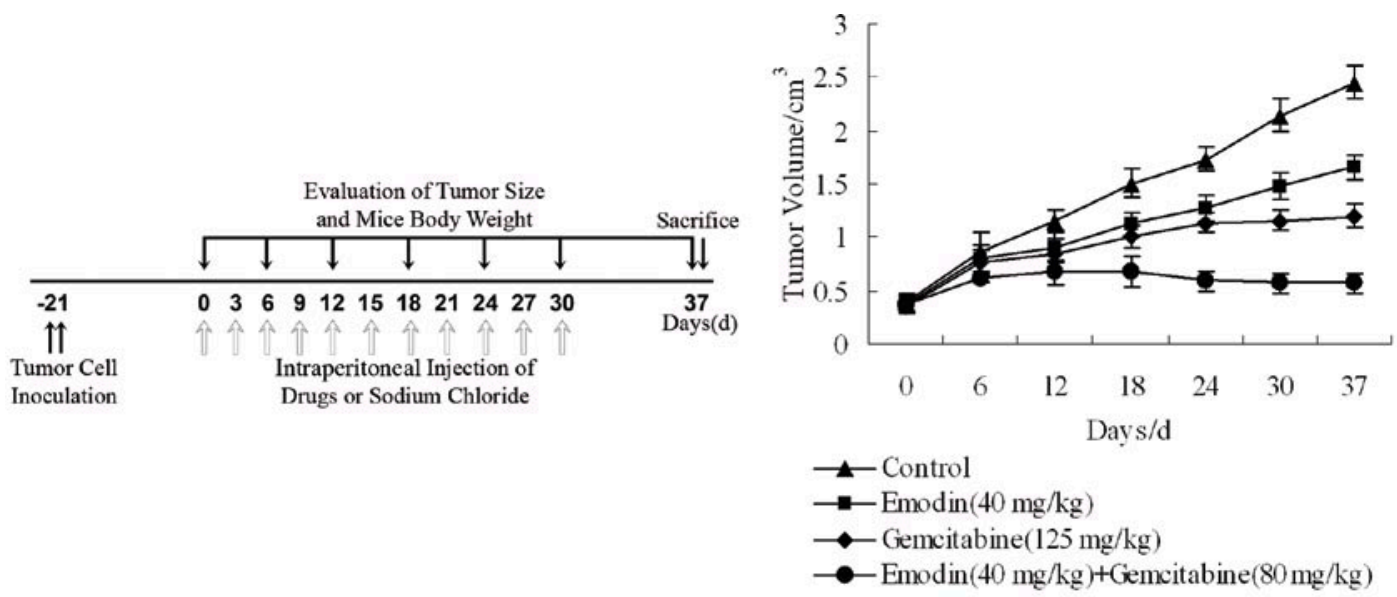

(A)

(B)
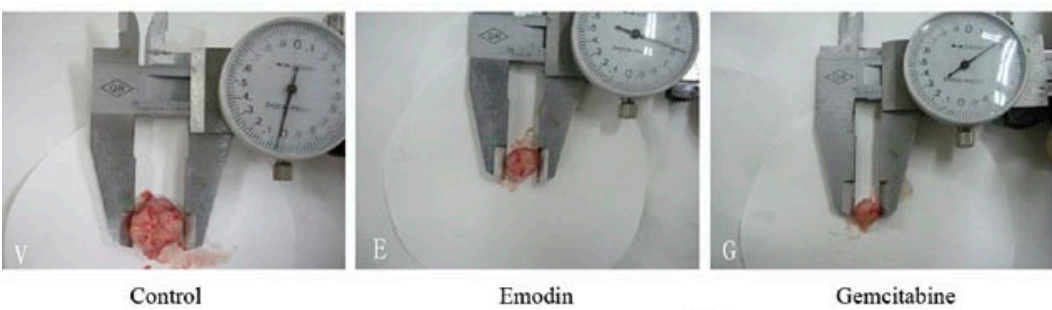

(C)

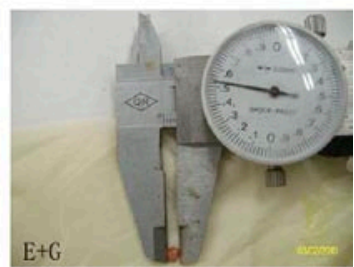

Emodin+Gemcitabine

Figure 3. Effects of different treatments on tumor size. (A) Schematic overview of the study protocol. (B) The tumor volume of mice in different groups was measured on indicated days. (C) One week after the final injection (Day 37), mice were sacrificed and tumors were removed. Examples of solid tumors are shown.

Table I. Effect of combination treatment on tumor growth inhibition.

\begin{tabular}{lcccc}
\hline Group & Drug dose $(\mathrm{mg} / \mathrm{kg})$ & Tumor weight $(\mathrm{g})$ & Tumor volume $\left(\mathrm{cm}^{3}\right)$ & Inhibition rate $(\%)$ \\
\hline Sodium chloride & 0 & $2.38 \pm 0.15$ & $2.45 \pm 0.16$ & 0 \\
Emodin $(\mathrm{E})$ & 40 & $1.68 \pm 0.13^{\mathrm{a}}$ & $1.66 \pm 0.11^{\mathrm{a}}$ & 37.5 \\
Gemcitabine $(\mathrm{G})$ & 125 & $1.32 \pm 0.05^{\mathrm{a}}$ & $1.20 \pm 0.12^{\mathrm{a}}$ & 59.1 \\
$(\mathrm{E})+(\mathrm{G})$ & $40(\mathrm{E})+80(\mathrm{G})$ & $0.56 \pm 0.07^{\mathrm{b}}$ & $0.57 \pm 0.08^{\mathrm{b}}$ & 90.8 \\
\hline
\end{tabular}

One week after the final injection (Day 37), mice were sacrificed, and tumor weight was measured. Tumor volume and inhibition rate were calculated as described in Materials and methods. ${ }^{\mathrm{P}}<0.05$ compared with sodium chloride treatment; ${ }^{\mathrm{b}} \mathrm{P}<0.05$ compared with sodium chloride, emodin or gemcitabine treatment.

significantly down-regulated the expression of Ki-67 in tumor tissues compared with other groups $(\mathrm{P}<0.05)$. As apoptosis is one major pathway which leads tumor cells to death, we investigated apoptotic cell death induced by drug treatment. In vivo, we found inhibition of cell growth was also correlated with apoptotic cell death. As shown in Fig. 4C, increased TUNEL-positive cells were observed in drug therapy groups, and combination treatment remarkably promoted the apoptotic cell death. Quantified data revealed that combination therapy with emodin plus gemcitabine dramatically elevated integrated optical density (IOD) as compared with other groups $(\mathrm{P}<0.01)$ (Fig. 4D). Above results were consistent with our in vitro results.

Immunohistochemistry shows combination treatment reduces Bcl-2/Bax ratio, promotes caspase-3 activation and CytC release. Decreased $\mathrm{Bcl}-2 / \mathrm{Bax}$ ratio, activation of caspase-3 and $\mathrm{CytC}$ release are recognized as the key events that mediate the apoptotic pathway. To clarify the mechanism of emodin plus gemcitabine-promoted apoptotic cell death in tumor tissues, the expression of anti-apoptotic protein Bcl-2, pro-apoptotic protein Bax, active caspase-3 and CytC were assessed by immunohistochemistry. As revealed in Fig. 5, reduced $\mathrm{Bcl}-2 / \mathrm{Bax}$ ratio, but enhanced caspase- 3 activation and $\mathrm{CytC}$ release from mitochondrial were observed after drug injection $(\mathrm{P}<0.01$ compared with control). Importantly, combination therapy further promoted the reduction of $\mathrm{Bcl}-2 / \mathrm{Bax}$ ratio $(\mathrm{P}<0.01$ compared with monotherapy with either agent) (Fig. 5B). The ratio of $\mathrm{Bcl}-2 / \mathrm{Bax}$ is essential for regulating $\mathrm{CytC}$ release from the mitochondria as well as caspase-3 cleavage. Immunohistochemical analysis confirmed the elevated cytosolic $\mathrm{CytC}$ level and activated caspase-3 

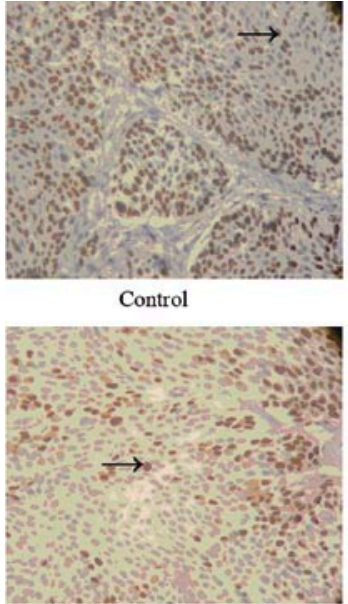

Gemcitabine

(A)

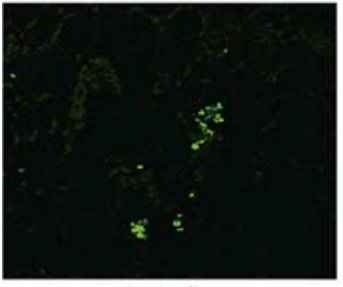

Control

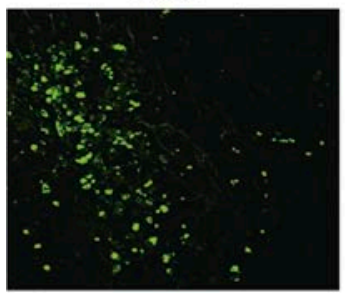

Gemcitabine

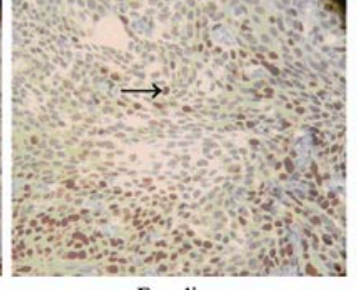

Emodin

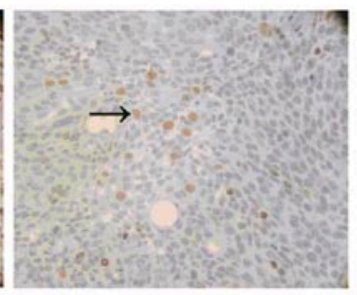

Emodin+Gemcitabine

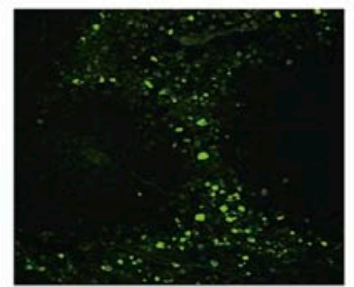

Emodin

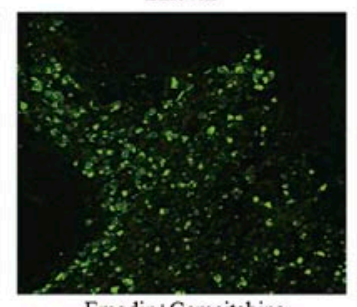

Emodin+Gemcitabine

(C)

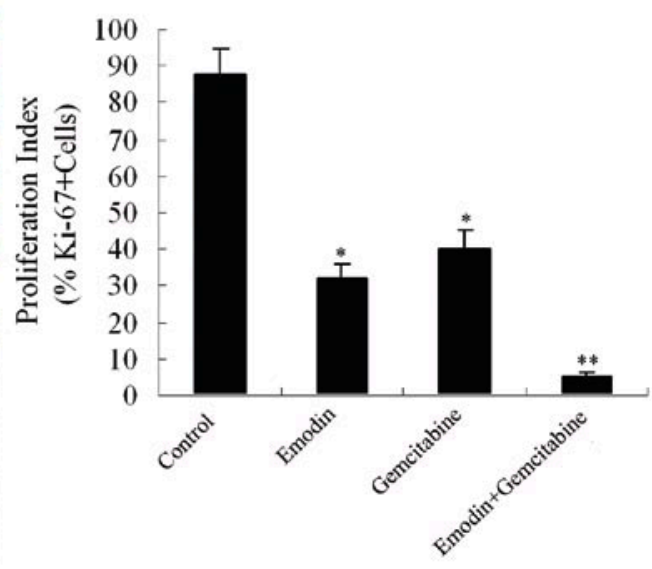

(B)

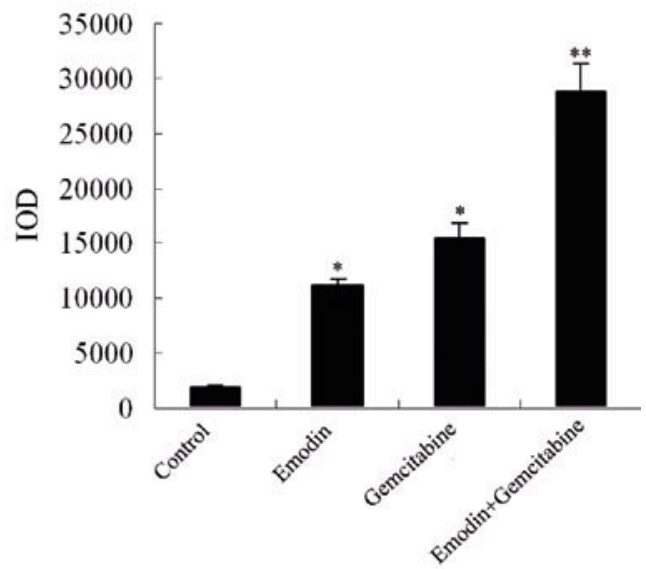

(D)

Figure 4. Determination of proliferation suppression and apoptotic cell death promoted by combination treatment. (A) Immunohistochemical analysis of proliferation marker Ki-67 indicates the inhibition of pancreatic cancer cell proliferation in emodin alone or in combination with gemcitabine-treated groups of animals. Arrows show Ki-67 positive cells (x400). (B) Quantification of Ki-67+ cells. Columns, the mean of triplicate; bars, SE. (C) Apoptosis of the tumor cells was demonstrated by TUNEL assay. Increased TUNEL-positive cells were found in combination treatment group (x400). (D) TUNEL staining was further quantified and presented as average IOD level. ${ }^{*} \mathrm{P}<0.01$ compared with sodium chloride treatment; ${ }^{* *} \mathrm{P}<0.01$ compared with sodium chloride, emodin or gemcitabine treatment.

protein expression in the combination treatment group $(\mathrm{P}<0.01$ compared with mono-therapy or with either agent) (Fig. 5C).

Further detection of Bcl-2/Bax ratio, caspase-3 activation and $\mathrm{CytC}$ release. Similar results to the above in immunohistochemistry were obtained from Western blot analysis (Fig. 6). Our results of Western blotting show obviously reduced Bcl-2/Bax ratio and strong caspase- 3 activation by combination of emodin and gemcitabine (Fig. 6A-C), thus, we assessed $\mathrm{CytC}$ release into the cytosol mitochondrial extract and mitochondria-free cytosolic extract by immunoblotting (Fig. 6A). A significant decrease in the mitochondrial CytC level in the combination treatment was observed compared with other groups, while appearance of CytC in the cytosol was significantly up-regulated compared with other groups (Fig. 6D). These data demonstrated combination therapy with both emodin and gemcitabine promoted tumor cell apoptosis via down-regulation of $\mathrm{Bcl}-2 / \mathrm{Bax}$ ratio, activation of caspase-3 and $\mathrm{CytC}$ release from mitochondria to the cytosol.

\section{Discussion}

In recent years, research of using natural substances to enhance the chemotherapeutic effect of gemcitabine was widespread. A number of studies have shown that natural compounds can enhance the therapeutic effect of gemcitabine on pancreatic cancer (17-19). Emodin can inhibit the growth of various cancer cells, including pancreatic cancer (20-22), and has been shown to increase sensitivity of paclitaxel, cisplatin, and etoposide, doxorubicin, celecoxib and arsenic trioxide and other drugs inducing apoptosis (23-25), including significantly enhanced anti-tumor and pro-apoptotic effect of gemcitabine on pancreatic cancer Panc-1 and Bxpc-3 cells (26). But the study in vivo on the mechanism of the enhanced 


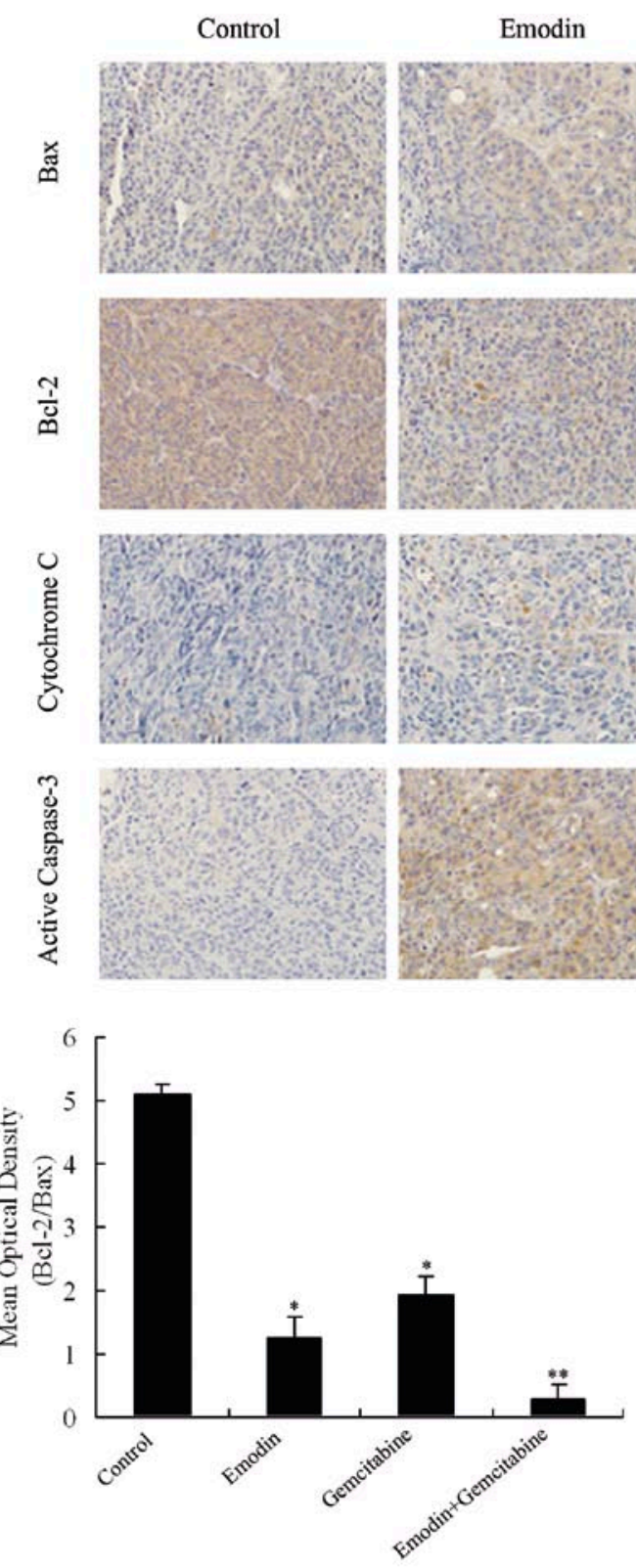

(B)
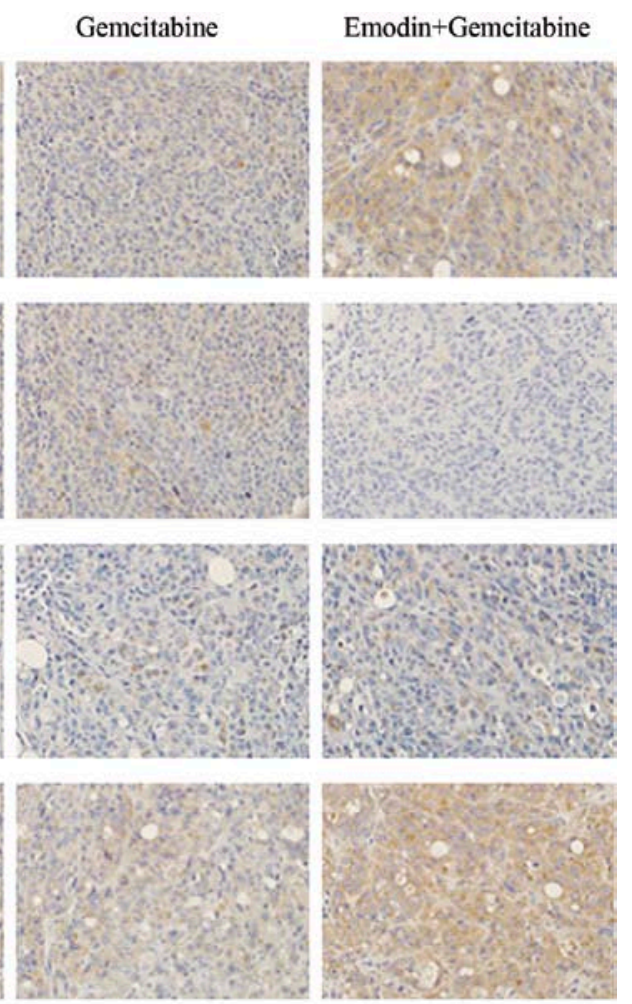

(A)

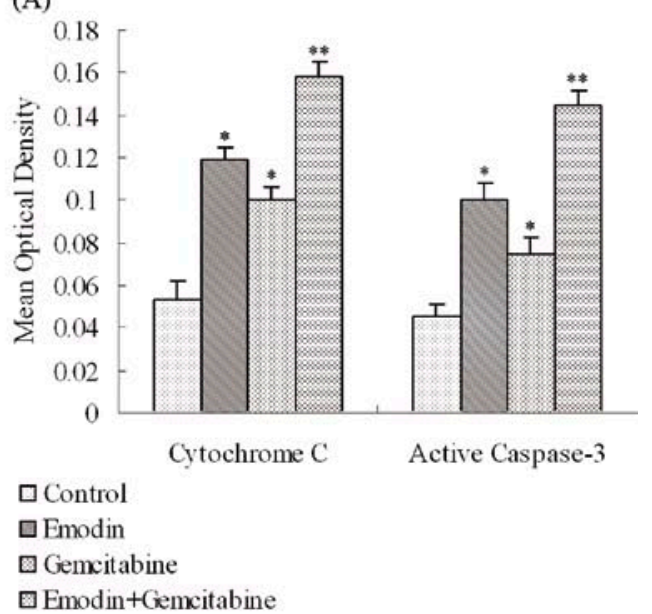

(C)

Figure 5. Combination treatment reduces the Bcl-2/Bax ratio, promotes caspase-3 activation and CytC release. (A) One week after the final injection (Day 37), the protein expression of Bcl-2, Bax, active caspase-3 and CytC were assessed by immunohistochemistry (x400). (B and C) Quantification data. ${ }^{*} \mathrm{P}<0.01$ compared with sodium chloride treatment; ${ }^{* *} \mathrm{P}<0.01$ compared with sodium chloride, emodin or gemcitabine treatment.

effect by combination of emodin and gemcitabine was absent. For the first time, we found, in vivo, emodin sensitized pancreatic cancer cell line SW1990 to gemcitabine through down-regulation of $\mathrm{Bcl}-2 / \mathrm{Bax}$ ratio and increasing release of $\mathrm{CytC}$ from mitochondria to cytosol. And interestingly, we first found that emodin enhanced the effect of gemcitabine on pancreatic cancer in vivo, even if the dose of gemcitabine was reduced.

Consistent with previous study by Guo et al (26), we also found in vitro emodin can sensitize pancreatic cancer to apoptosis induced by gemcitabine. Furthermore, we firstly found similar results in in vivo experiments, as evidenced by TUNEL assay and analysis of caspase-3 activation by immu- nohistochemistry and immunoblotting. We subsequently investigated the mechanism of how emodin potentiated the pro-apoptotic effect of gemcitabine in vivo. An upstream event in activation of the caspase-3 is the release of CytC from mitochondria which can trigger caspase-3 leading to apoptosis. Many cancer-preventive and chemotherapeutic agents have been shown to activate the apoptotic pathway that involves the release of $\mathrm{CytC}$ from mitochondria, which then oligomerizes with procaspase-9 leading to formation of active caspase- 9 that activates downstream executioner caspases such as caspase-3 and caspase-7 (27). It has been reported that emodin can down-regulate Bcl-2 expression, up-regulate Bax level, trigger $\mathrm{CytC}$ release, and subsequently activate 


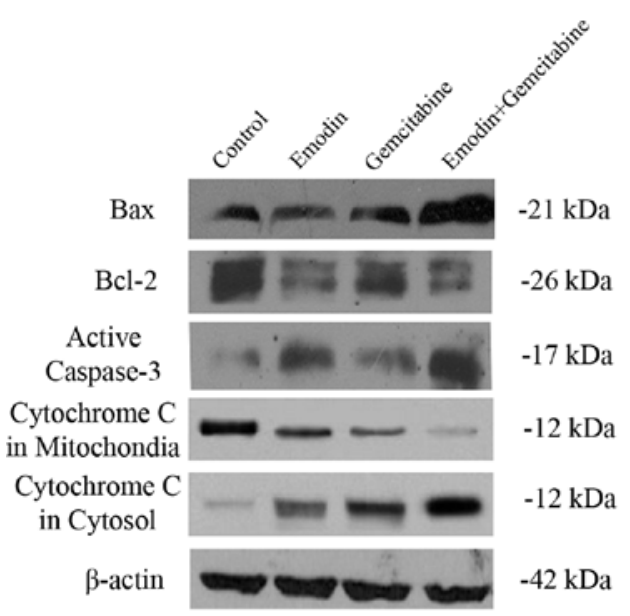

(A)

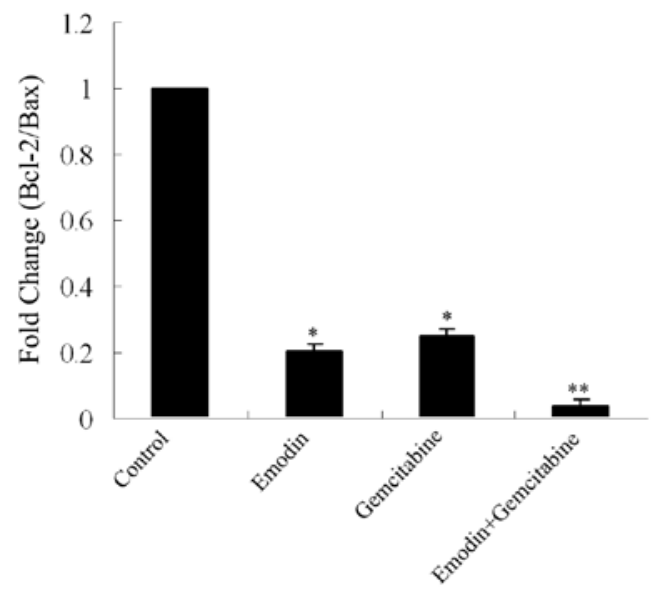

(C)

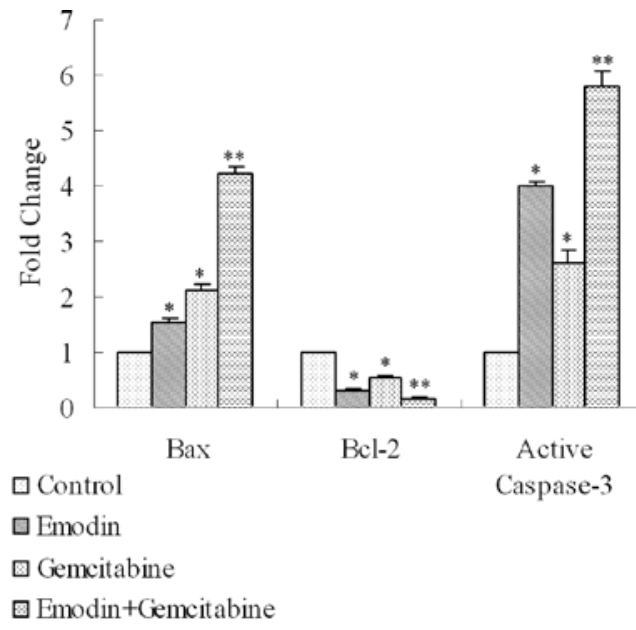

(B)

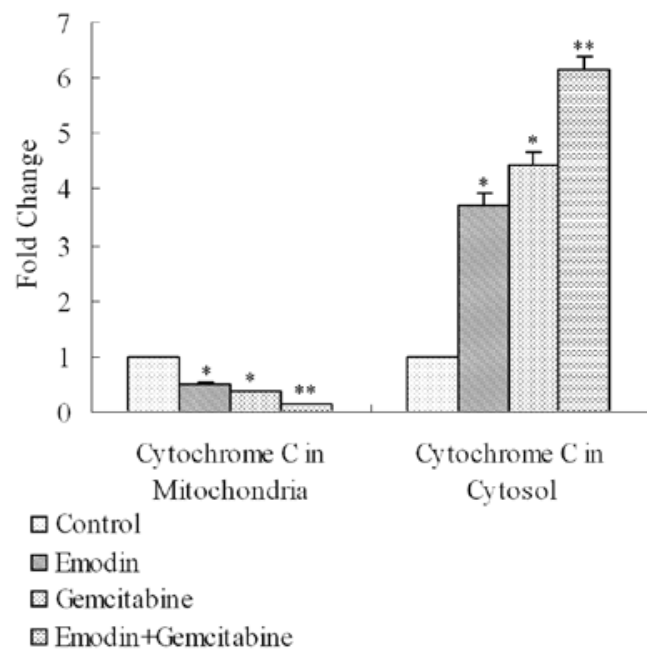

(D)

Figure 6. Western blotting demonstrated that combination treatment reduced Bcl-2/Bax ratio, promoted caspase-3 activation and CytC release. One week after the final injection (Day 37), the protein expression of Bcl-2, Bax, active caspase-3 and CytC were assessed by Western blotting (A), CytC was analyzed in differentially separated mitochondrial supernatants and cytosol prepared from tumor tissues of four experimental groups showing loss of mitochondrial $\mathrm{CytC}$ and its appearance in the cytosol. $\beta$-actin protein as loading control is shown. Quantified data are presented in (B-D). ${ }^{*} \mathrm{P}<0.01 \mathrm{compared}$ with sodium chloride treatment; ${ }^{* *} \mathrm{P}<0.01$ compared with sodium chloride, emodin or gemcitabine treatment.

caspases-2, 3, 9, and induce apoptosis in other kinds of cancer cells $(15,16)$. Our results are consistent with these reports, showing increased levels of active caspase- 3 in combination group of emodin and gemcitabine, what is more, concomitant with a decrease in mitochondrial $\mathrm{CytC}$ which was further confirmed by the increase in cytosolic $\mathrm{CytC}$ in combination group compared to control or single agent groups. These result suggested that emodin enhances the pro-apoptotic effect of gemcitabine on subcutaneously tranplanted pancreatic cancer by regulating $\mathrm{CytC}$ release.

The balance of pro-apoptotic and anti-apoptotic proteins, such as the Bcl-2/Bax ratio, is essential in cell apoptosis, and alteration of this balance allows sensitization to apoptotic effect of chemotherapy. Bax up-regulation in breast (28) and pancreatic cancer (29) is associated with longer survival, which seems to be related to Bax homodimer formation or an imbalance in the Bcl-2/Bax ratio towards Bax, which promotes cell death (30-32). Furthermore, Bcl-2 and Bax respectively suppresses and promotes $\mathrm{CytC}$ to release from mitochondria, so we further investigated the variation of $\mathrm{Bcl}-2 / \mathrm{Bax}$ ratio. In this study, we observed a remarkably decreased Bcl-2/ Bax ratio in tumor tissues after combination treatment as revealed by immunohistochemical and Western blot analysis, demonstrating emodin enhances the pro-apoptotic activity of gemcitabine in pancreatic cancer cells via down-regulating the Bcl-2/Bax ratio. Our study revealed that emodin might be able to down-regulate $\mathrm{Bcl}-2$ expression, up-regulate Bax level, triggers the $\mathrm{CytC}$ release, and subsequently activates caspase-3 and induces cell apoptosis.

Several randomized studies have shown significant increase in patient response rate by the use of combinations of different class of chemotherapeutic agents, but the major problem is due to treatment associated high toxicity with no added benefit in overall survival (33-35). However, these limitations could be overcome by the use of rational chemotherapeutic combinations, in which toxic agents are used in lower doses, and the efficacy of treatment is complemented by using a non-toxic agent. Based on this 
rationale, we used emodin in combination with gemcitabine to test its efficacy against pancreatic cancer transplanted tumors. Our results showed that lower dose of gemcitabine combined with emodin exhibited enhanced suppression of tumor growth compared to high dose of gemcitabine therapy. This result suggested emodin combined with gemcitabine might be a new effective and low toxic therapeutic strategy for pancreatic cancer.

In summary, this study showed that emodin combined with lower dose of gemcitabine can significantly enhance the anti-tumor effect of gemcitabine on pancreatic cancer SW1990 cell transplanted tumors through inducing apoptosis of tumor cells, the mechanism of which may be that emodin decreases $\mathrm{Bcl}-2 / \mathrm{Bax}$ ratio, and then causes the release of $\mathrm{CytC}$, from mitochondria into cytoplasm, thus leading to more significant apoptosis of tumor cells via activation of caspase-3. However, further mechanistic studies could be useful to fully support our strategy for the treatment of patients with pancreatic tumors.

\section{Acknowledgements}

This study was supported by grants from the Natural Science Foundation of Zhejiang Province, China (Y2080708). We thank the entire staff of the Animal Experimental Center and scientific research platform in Wenzhou Medical College for helpful assistance.

\section{References}

1. Jemal A, Thomas A, Murray T and Thun M: Cancer statistics, 2002. CA Cancer J Clin 52: 23-47, 2002.

2. Mangray S and King TC: Molecular pathobiology of pancreatic adenocarcinoma. Front Biosci 3: D1148-D1160, 1998.

3. Hilbig A and Oettle H: Adjuvant therapy of pancreatic cancer. Expert Rev Anticancer Ther 10: 485-491, 2010.

4. Oettle H, Post S, Neuhaus P, et al: Adjuvant chemotherapy with gemcitabine vs observation in patients undergoing curativeintent resection of pancreatic cancer: a randomized controlled trial. JAMA 297: 267-277, 2007.

5. Tempero MA, Behrman S, Ben-Josef E, et al: Pancreatic adenocarcinoma: clinical practice guidelines in oncology. J Natl Compr Canc Netw 3: 598-626, 2005.

6. Oettle $\mathrm{H}$ and Riess H: Gemcitabine in combination with 5 -fluorouracil with or without folinic acid in the treatment of pancreatic cancer. Cancer 95: 912-922, 2002.

7. Burris HA III, Moore MJ, Andersen J, et al: Improvements in survival and clinical benefit with gemcitabine as first-line therapy for patients with advanced pancreas cancer: a randomized trial. J Clin Oncol 15: 2403-2413, 1997.

8. Burris $\mathrm{H}$ and Storniolo AM: Assessing clinical benefit in the treatment of pancreas cancer: gemcitabine compared to 5-fluorouracil. Eur J Cancer 33 (Suppl. 1): S18-S22, 1997.

9. Bader Y, Hartmann J, Horvath Z, et al: Synergistic effects of deuterium oxide and gemcitabine in human pancreatic cancer cell lines. Cancer Lett 259: 231-239, 2008.

10. Nakagawa T, Shimizu M, Shirakami Y, Tatebe H, Yasuda I, Tsurumi $\mathrm{H}$ and Moriwaki $\mathrm{H}$ : Synergistic effects of acyclic retinoid and gemcitabine on growth inhibition in pancreatic cancer cells. Cancer Lett 273: 250-256, 2009.

11. Lee SH, Ryu JK, Lee KY, et al: Enhanced anti-tumor effect of combination therapy with gemcitabine and apigenin in pancreatic cancer. Cancer Lett 259: 39-49, 2008.

12. Wang SJ, Gao Y, Chen H, et al: Dihydroartemisinin inactivates NF-kappaB and potentiates the anti-tumor effect of gemcitabine on pancreatic cancer both in vitro and in vivo. Cancer Lett 293 99-108, 2010

13. Su YT, Chang HL, Shyue SK and Hsu SL: Emodin induces apoptosis in human lung adenocarcinoma cells through a reactive oxygen species-dependent mitochondrial signaling pathway. Biochem Pharmacol 70: 229-241, 2005
14. Yi J, Yang J, He R, Gao F, Sang H, Tang X and Ye RD: Emodin enhances arsenic trioxide-induced apoptosis via generation of reactive oxygen species and inhibition of survival signaling. Cancer Res 64: 108-116, 2004.

15. Gerlier D and Thomasset N: Use of MTT colorimetric assay to measure cell activation. J Immunol Methods 94: 57-63, 1986

16. Guha S, Eibl G, Kisfalvi K, et al: Broad-spectrum G proteincoupled receptor antagonist, [D-Arg1,D-Trp5,7,9,Leu11]SP: a dual inhibitor of growth and angiogenesis in pancreatic cancer. Cancer Res 65: 2738-2745, 2005.

17. Jung CP, Motwani MV and Schwartz GK: Flavopiridol increases sensitization to gemcitabine in human gastrointestinal cancer cell lines and correlates with down-regulation of ribonucleotide reductase M2 subunit. Clin Cancer Res 7: 2527-2536, 2001.

18. Banerjee S, Zhang Y, Ali S, et al: Molecular evidence for increased antitumor activity of gemcitabine by genistein in vitro and in vivo using an orthotopic model of pancreatic cancer. Cancer Res 65: 9064-9072, 2005.

19. Kunnumakkara AB, Guha S, Krishnan S, Diagaradjane P, Gelovani J and Aggarwal BB: Curcumin potentiates antitumor activity of gemcitabine in an orthotopic model of pancreatic cancer through suppression of proliferation, angiogenesis, and inhibition of nuclear factor-kappaB-regulated gene products. Cancer Res 67: 3853-3861, 2007.

20. Cai J, Razzak A, Hering J, Saed A, Babcock TA, Helton S and Espat NJ: Feasibility evaluation of emodin (rhubarb extract) as an inhibitor of pancreatic cancer cell proliferation in vitro. JPEN J Parenter Enteral Nutr 32: 190-196, 2008.

21. Chang CJ, Ashendel CL, Geahlen RL, McLaughlin JL and Waters DJ: Oncogene signal transduction inhibitors from medicinal plants. In Vivo 10: 185-190, 1996.

22. Cha TL, Qiu L, Chen CT, Wen Y and Hung MC: Emodin downregulates androgen receptor and inhibits prostate cancer cell growth. Cancer Res 65: 2287-2295, 2005.

23. Zhang L and Hung MC: Sensitization of HER-2/neu-overexpressing non-small cell lung cancer cells to chemotherapeutic drugs by tyrosine kinase inhibitor emodin. Oncogene 12: 571-576, 1996.

24. Zhang L, Lau YK, Xia W, Hortobagyi GN and Hung MC: Tyrosine kinase inhibitor emodin suppresses growth of HER-2/ neu-overexpressing breast cancer cells in athymic mice and sensitizes these cells to the inhibitory effect of paclitaxel. Clin Cancer Res 5: 343-353, 1999.

25. Lai GH, Zhang Z and Sirica AE: Celecoxib acts in a cyclooxygenase-2-independent manner and in synergy with emodin to suppress rat cholangiocarcinoma growth in vitro through a mechanism involving enhanced Akt inactivation and increased activation of caspases-9 and -3 . Mol Cancer Ther 2: 265-271, 2003.

26. Guo Q, Chen Y, Zhang B, Kang M, Xie Q and Wu Y: Potentiation of the effect of gemcitabine by emodin in pancreatic cancer is associated with survivin inhibition. Biochem Pharmacol 77: 1674-1683, 2009.

27. Hengartner MO: The biochemistry of apoptosis. Nature 407: 770-776, 2000.

28. Bargou RC, Daniel PT, Mapara MY, et al: Expression of the bcl-2 gene family in normal and malignant breast tissue: low bax-alpha expression in tumor cells correlates with resistance towards apoptosis. Int J Cancer 60: 854-859, 1995.

29. Friess H, Lu Z, Graber HU, et al: bax, but not bcl-2, influences the prognosis of human pancreatic cancer. Gut 43: 414-421, 1998.

30. Oltvai ZN, Milliman CL and Korsmeyer SJ: Bcl-2 heterodimerizes in vivo with a conserved homolog, Bax, that accelerates programmed cell death. Cell 74: 609-619, 1993.

31. Findley HW, Gu L, Yeager AM and Zhou M: Expression and regulation of $\mathrm{Bcl}-2, \mathrm{Bcl}-\mathrm{xl}$, and $\mathrm{Bax}$ correlate with p53 status and sensitivity to apoptosis in childhood acute lymphoblastic leukemia. Blood 89: 2986-2993, 1997.

32. Miyashita T, Harigai M, Hanada M and Reed JC: Identification of a p53-dependent negative response element in the bcl-2 gene. Cancer Res 54: 3131-3135, 1994.

33. Arends JJ, Sleeboom HP, Leys MB, et al: A phase II study of raltitrexed and gemcitabine in patients with advanced pancreatic carcinoma. Br J Cancer 92: 445-448, 2005.

34. Berlin JD and Rothenberg ML: Chemotherapeutic advances in pancreatic cancer. Curr Oncol Rep 5: 219-226, 2003.

35. Diaz-Rubio E: New chemotherapeutic advances in pancreatic, colorectal, and gastric cancers. Oncologist 9: 282-294, 2004. 